\title{
Montagem de laboratório da área da Construção Civil: Relato de experiência na ótica do ensino-aprendizagem
}

\author{
Laboratory assembly of the Civil Construction Area: Experience Report from the teaching- \\ learning outline \\ Montaje de laboratorio en el área de Construcción Civil: Informe de experiencia desde la \\ perspectiva de enseñanza-aprendizaje
}

\begin{abstract}
Resumo
O ensino da área da Construção Civil no Brasil possui bases pedagógicas que, na maioria dos casos, não ligam diretamente o aluno a situações reais da sociedade em que estão imersos. Dessa forma, é muito comum a potencialização natural do ensino teórico dissociado da prática, vezes pelo tempo de cumprimento da matriz curricular, vezes pela própria complexidade de conteúdos. Todavia, essa naturalidade do ensino teórico tem prejudicado a formação técnica de alguns profissionais que chegam ao mercado de trabalho sem noção real do desenvolvimento de uma obra e da ligação de suas partes. Assim, a interdisciplinaridade entre as etapas construtivas e o uso de laboratórios para simulações de testes reais podem agregar à melhoria do processo de ensino-aprendizagem. Esse estudo traz, a partir de um relato de experiência, o processo de montagem de um laboratório da área da Construção Civil (Técnicas Construtivas) em um campus da rede do Instituto Federal, considerando análises críticas sobre o favorecimento do ensino e da aprendizagem em espaços como esse. Foram seguidas etapas metodológicas que puderam apresentar os desafios e as recompensas na insistência de montagem desse laboratório; como, por exemplo, o resgate gradual do processo de "ensinar fazendo" na área da Construção Civil nesse campus, a apropriação natural do espaço pela comunidade acadêmica e o início da conscientização de que o processo de educação existe para propagar e aperfeiçoar conhecimentos para melhoria da sociedade em que se está inserido.
\end{abstract}

Palavras-chave: Interdisciplinaridade; Ensino; Aprendizagem; Educação; Trabalho; Sociedade.

\begin{abstract}
Teaching in the field of Civil Construction in Brazil has pedagogical bases that, in most cases, do not directly link the student to real situations in the society in which they are immersed. Thus, it is very common to naturally enhance theoretical teaching dissociated from practice, sometimes due to the time it takes to complete the curriculum, sometimes due to the complexity of the content itself. However, this naturalness of theoretical teaching has hindered the training of some professionals who arrive in the job market without a real sense of the development of a work and the connection of its parts. Therefore, the interdisciplinarity between the construction stages and the use of laboratories for real test simulations can add to the improvement of the teaching-learning process. This study brings, from an experience report, the process of setting up a laboratory in the area of Civil Construction (Constructive Techniques) on a campus of the Federal Institute's network in Brazil, considering critical analyzes on the favor of teaching and learning in spaces like this. Methodological steps were followed that could present challenges and rewards in the insistence of setting up this laboratory; such as, for example, the gradual rescue of the process of practical teaching in the area of civil construction on this campus, a natural appropriation of space by the academic community and the beginning of the awareness that the education process exists to propagate and improve knowledge to improve society in which it is inserted.
\end{abstract}

Keywords: Interdisciplinarity; Teaching; Learning; Education; Work; Society.

\section{Resumen}

La docencia en el área de la Construcción Civil en Brasil tiene bases pedagógicas que, en la mayoría de los casos, no vinculan directamente al alumno con situaciones reales de la sociedad en la que se encuentra inmerso. Así, es muy común potenciar de forma natural la enseñanza teórica disociada de la práctica, a veces por el tiempo que se tarda en 
completar el currículo, a veces por la complejidad del propio contenido. Sin embargo, esta naturalidad de la enseñanza teórica ha dificultado la formación técnica de algunos profesionales que llegan al mercado laboral sin un sentido real del desarrollo de una obra y la conexión de sus partes. Así, la interdisciplinariedad entre las etapas constructivas y el uso de laboratorios para simulaciones de pruebas reales puede contribuir a la mejora del proceso de enseñanzaaprendizaje. Este estudio trae, a partir de una experiencia, el proceso de instalación de un laboratorio en el área de Construcción Civil (Técnicas Constructivas) en un campus de la red del Instituto Federal en Brasil, considerando análisis críticos sobre la promoción de la enseñanza y el aprendizaje en los espacios como ese. Se siguieron pasos metodológicos que podrían presentar desafíos y recompensas en la insistencia de montar este laboratorio; como, por ejemplo, el rescate paulatino del proceso de "enseñar haciendo" en el área de Construcción Civil de este campus, la apropiación natural del espacio por parte de la comunidad académica y el inicio de la conciencia de que el proceso educativo existe para difundir y mejorar el conocimiento para la mejora de la sociedad en la que se inserta.

Palabras clave: Interdisciplinariedad; Ensenãnza; Aprendizaje; Educación; Trabajo; Sociedad.

\section{Introdução}

Existe uma relação estreita e, muitas vezes, negligenciada entre trabalho e educação. Conforme se lê em Saviani (2007) e Frigotto (2001), o trabalho faz parte da formação ontológica do ser humano, uma vez que busca modificar o meio para adequálo às suas necessidades de sobrevivência e desejos de evolução. Com isso, os indivíduos de um grupo ou sociedade vão adquirindo novos conhecimentos e aperfeiçoando-os na sua transmissão ao longo das gerações. Nesse processo de repasse do conhecimento, configura-se, então, o ato da educação, que está intimamente ligado ao trabalho, bem como à sociedade em que se está inserido.

Assim, o processo de educação vai adaptando-se ao grupo, seus princípios, suas necessidades de transformação do meio (trabalho), suas crenças e sua história (Saviani, 2007). Todavia, de acordo com essa autora, ao longo dos tempos, com a divisão de classes e o surgimento de uma era meramente tecnicista de um lado e extremamente teórica de outro, a nitidez dessa relação de trabalho e educação foi se apagando e perdendo sua importância. Essa relação pouco emancipadora gerou na sociedade um ciclo vicioso de labuta focada apenas na busca do salário para sobrevivência, conforme aponta Mota, Araújo e Santos (2018), sem todavia ter um entendimento real da necessidade desse elo. Estes autores trazem a importância do surgimento dos Institutos Federais de Educação (IF's) como uma inovação formativa educacional que coloca o trabalho como um instrumento de libertação dos trabalhadores. Os IF's, portanto, desempenharam e desempenham um resgate do fortalecimento do tripé entre educação, trabalho e sociedade, uma vez que tem por base de surgimento o princípio técnico citado por Saviani (1994), o do "ensinar fazendo", aliado à formação de profissionais críticos e sabedores de seu papel na sociedade.

Porém, como um processo natural de evolução e a inclusão de cursos superiores junto ao ensino técnico, os IF's foram se fortalecendo em uma configuração de instituição de ensino que trabalha graduação, pós-graduação, ensino médio, técnico e tecnológico. Nesse formato, pois, existe uma linha tênue que requer um certo cuidado de não se perder a base do "ensinar fazendo" posta, à princípio, aos cursos técnicos e fazer com que os cursos de graduação ganhem por estar próximos de um princípio que vai além das bases teóricas.

Barato (2015a) fala sobre o cuidado, justamente dentro dos IF's, de não se negligenciar a prática no ensino profissional e a importância de não se deixar enfraquecer o uso de laboratórios pelo corpo docente nessas Instituições. Para Barato (2015b), o ensino distante da oficina, do laboratório ou das situações de desenvolvimento de técnicas de trabalho ignora o modo pelo qual os trabalhadores constroem os quadros de valores típicos de suas profissões.

Assim, o presente trabalho é pautado no questionamento da existência de uma potencialização do ensino teórico dissociado da prática dentro dos IF's e na inquietação de se identificar uma forma de resgate da técnica do "aprender fazendo" a partir do envolvimento do grupo acadêmico em espaços laboratoriais.

Com isso, o objetivo deste artigo é apresentar, por meio de um relato de experiência, o processo de montagem de um laboratório da área da Construção Civil (Técnicas Construtivas) em um campus da rede do Instituto Federal, considerando análises críticas sobre o favorecimento do ensino e da aprendizagem em espaços como esse. 


\section{Ensino-Aprendizagem e o Uso de Laboratório}

Estudos sobre o processo de ensino-aprendizagem são destaques em ambientes acadêmicos. Todavia, no âmbito da Construção Civil nacional ainda se mostram incipientes as pesquisas que abordam um caráter mais reflexivo e pedagógico em torno de questões de aprendizado nessa área.

Silva Junior, Fontenele e Silva (2013) relatam que tanto o corpo docente como discente da área da Construção fica, na maioria dos casos, imerso em um processo pedagógico tradicional, repetindo métodos de ensino que parecem ser imutáveis. Muitas vezes, isso se deve ao fato da própria complexidade de conteúdos e do tempo para se cumprir a matriz curricular. Assim, o ponto principal, segundo Cardoso e Silva Lima (2012), é identificar formas de melhor aproveitar o tempo disponível à formação dos alunos e, com isso, criar condições de transmitir conhecimentos, habilidades e atitudes necessárias ao profissional dessa área.

Pereira (2005) diz ser possível, mesmo diante de grades curriculares rígidas, aprimorar o processo de ensinoaprendizagem, trazendo métodos e técnicas que facilitem a comunicação dos conceitos e conteúdos. Para essa autora, o ensino da engenharia, de um modo geral, pode até estar cumprindo bem o seu papel tradicional, mas carece de profundas reflexões sobre sua prática educacional, visto as exigências de mercado hoje serem cada vez mais específicas. Bernardinis, Zau e Pacheco (2017), por sua vez, afirmam que as falhas e deficiências encontradas atualmente nos métodos de ensino da Construção Civil no Brasil representam um problema tanto para os estudantes quanto para o mercado que os empregará futuramente, pois estes, na maioria dos casos, saem do curso com uma vivência ou afinidade dos materiais e das situações práticas aquém do esperado.

Assim, antes de se ter um bom profissional, é preciso se formar um bom estudante. Em 1991, Felder e Soloman propõem um modelo conhecido como Index of Learning Style (ILS) que investiga as formas como os aprendizes recebem e tratam as informações. No ILS, é apresentado um mecanismo para obtenção do índice de estilos de aprendizagem, ou seja, as preferências de aprendizagem de um indivíduo ou grupo de indivíduos (Felder \& Spurlin, 2005). Aplicando o método na Faculdade de Engenharia e Ciências da Universidade de Aalborg, Dinamarca, Kolmos e Holgaard (2008) mostram que os alunos de engenharia se configuram mais como ativos, sensíveis e visuais. Assim, eles propuseram métodos mais sistematizados com a inclusão da pesquisa no processo de ensino. Segundo esses autores, dessa forma, pode-se facilitar um equilíbrio entre a experimentação ativa e a reflexão. Não há dúvida, segundo eles, de que o experimento é um elemento importante no desenvolvimento da criatividade e que a associação à pesquisa pode levar os alunos a pularem de ideias de senso comum para ideias mais fundamentadas com base em experiência prática e reflexão teórica.

Valêncio (2000), ao falar do tripé de ensino, pesquisa e extensão na universidade pública brasileira, mostra que, ao se fragmentar o todo e isolar o conhecimento científico apenas no ensino, fragiliza-se o sujeito aprendiz na sua capacidade de interpretação múltipla. É necessário, portanto, que, através da pesquisa e também da extensão, a universidade pense o ensino junto à sociedade e não como um ser alheio a ela. Afinal, a educação existe para propagar o conhecimento e trazer melhorias para o coletivo. Desse modo, pois, é possível a academia pensar a aplicação prática do currículo acadêmico através do ensino, pesquisa e extensão e favorecer simultaneamente a interdisciplinaridade. Essa interdisciplinaridade, por fim, pode diluir fronteiras estabelecidas entre as diversas ciências e entre seus métodos específicos, conforme coloca Puhl e Dresch (2016). Corrêa e Naveiro (2001) e Formighieri e Lima (2019) falam da importância de adaptar a dinâmica dos cursos para a formação de profissionais mais conscientes da relação entre as etapas dos projetos que irão trabalhar. Eles alertam que, ao final do curso, estudantes da área da construção podem encontrar dificuldades até mesmo para entender a relação prática entre as disciplinas vistas, caso não seja eficiente a interrelação em sua matriz curricular.

$\mathrm{Na}$ maioria dos casos, existe, de fato, uma deficiência nos métodos de ensino quando se pensa em integrar as atividades técnicas das várias áreas de conhecimento, bem como deficiência em proporcionar ao aluno afinidade laboratorial e vivência com os materiais e técnicas a serem utilizados. Silva Junior et al. (2013) dizem existir uma pressão no ensino da engenharia para mudanças no formato de aprendizagem nesse curso. Para os autores, estas mudanças estão voltadas principalmente à melhoria 
de metodologias usadas em classe, como aulas expositivas em sala e complementação por meio de resolução de exercícios e práticas de laboratório; todavia, voltando-se o aluno não apenas para desenvolver habilidades básicas para obterem aprovação em provas e testes. Bernardinis et al. (2017) complementam que o principal problema é o fato dessas práticas não tornarem o aluno capaz de resolver problemas que o mundo real apresenta, mesmo tendo aprovação em todas as disciplinas exigidas pelo curso. Para as autoras, isso é um indício que existe uma provável falha no sistema educacional, nos métodos de avaliação e também na missão da universidade de preparar o aluno de maneira satisfatória para a resolução de problemas tangentes à realidade. Assim, Formighieri e Lima (2019) propõe que as atividades das disciplinas dessa área devem ser simuladas e baseadas em exercícios de prática profissional, usando laboratórios, por exemplo, com mecanismos contemporâneos em uma metodologia interdisciplinar, que se mostra tão relevante no processo de ensino-aprendizagem.

Desse modo, o ensino interdisciplinar pode ser suporte para conduzir, de maneira integrada, estudos laboratoriais na área da Construção Civil, despertando processos comparativos entre teoria e prática que venham a facilitar o entendimento dos diversos conteúdos (Figura 1). Com isso, o processo de ensino-aprendizagem consegue refletir o seu papel na sociedade e aperfeiçoar técnicas de trabalho a partir das interações entre pesquisa e extensão.

Figura 1 - Síntese ilustrativa sobre a importância do laboratório no processo de educação.

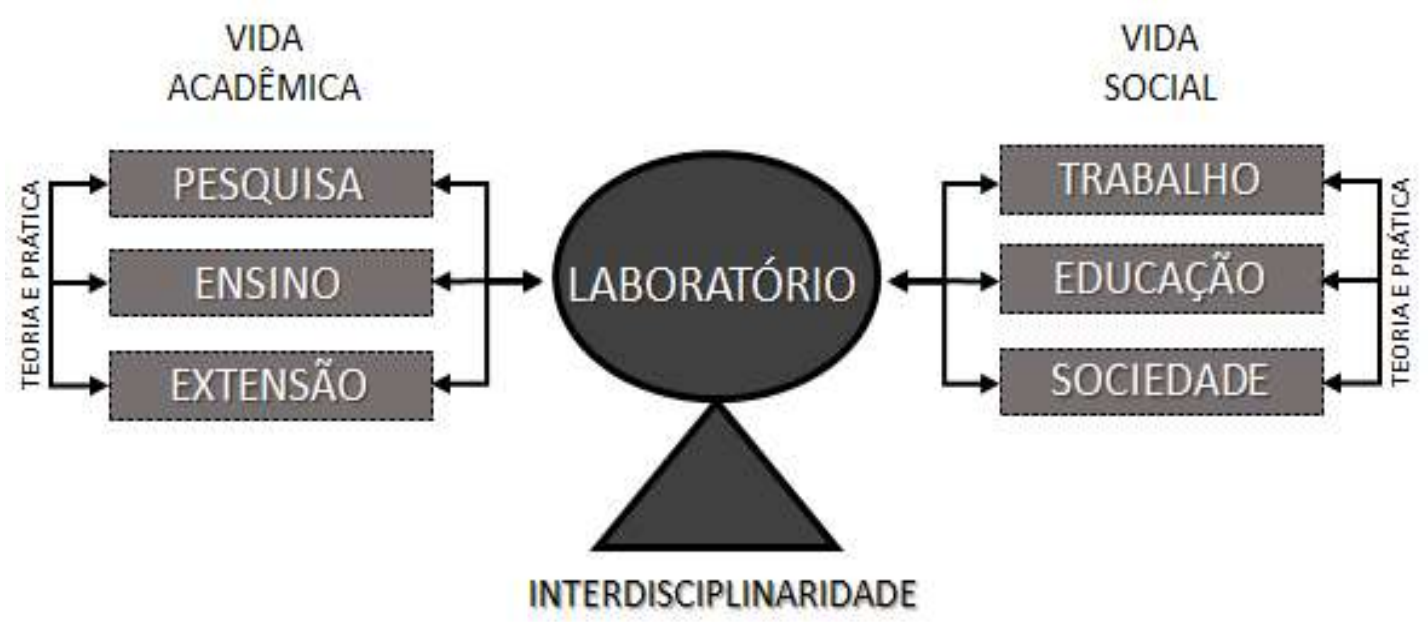

Fonte: Sistematizado pelas autoras.

Percebe-se aí, pois, uma oportunidade de melhoria no processo de "ensinar fazendo" na área da Construção Civil através do uso ampliado de laboratórios, levando simulações do trabalho real em busca da melhoria contínua. É urgente, portanto, fomentar a interdisciplinaridade por meio da pesquisa e extensão dentro da matriz curricular de cursos ligados à Construção Civil. Para tanto, ressalta Vega, Ribeiro, Padova e Ghisleni (2020), é necessário primeiramente o assunto estar presente no diálogo dos professores, de forma que estes estabeleçam vínculos e relações que sejam estendidos aos saberes disciplinares. Esse processo, segundo Puhl e Dresch (2016), gera o fortalecimento da base acadêmica, na qual cada dimensão traz suas contribuições de reforço do aprendizado para o grupo, favorecendo a inovação e o suporte na resolução de problemas reais da sociedade.

\section{Metodologia}

As pesquisas científicas podem ser caracterizadas segundo sua abordagem, segundo sua natureza, quanto aos seus objetivos e quanto aos seus procedimentos metodológicos (Silveira \& Córdova, 2009). Esse estudo é trazido com uma abordagem qualitativa, pois não se foca em números, mas sim em uma compreensão aprofundada sobre o tema em questão; de natureza aplicada, que, segundo Silveira e Córdova (2009), objetiva-se em gerar conhecimentos para aplicação prática, de modo a 
solucionar problemas específicos de interesses locais. Nesse caso, a partir do relato de experiência, busca-se propor formas de melhorar a Construção Civil local com a abordagem do ensino por meio de laboratório. A pesquisa apresenta também um objetivo exploratório e descritivo que, segundo Gil (2007), é muito utilizado em instituições educacionais e destina-se ao aprimoramento de ideias, fazendo-se associações entre diferentes variáveis. No caso desse estudo, adotaram-se os seguintes procedimentos de pesquisa para obtenção das diferentes variáveis de análise: Análise sobre Ensino-Aprendizagem, Pesquisa Documental, Estudo de Campo e Análise de Conteúdo (Figura 2).

Figura 2 - Percurso metodológico que tornou possível esse relato de experiência.

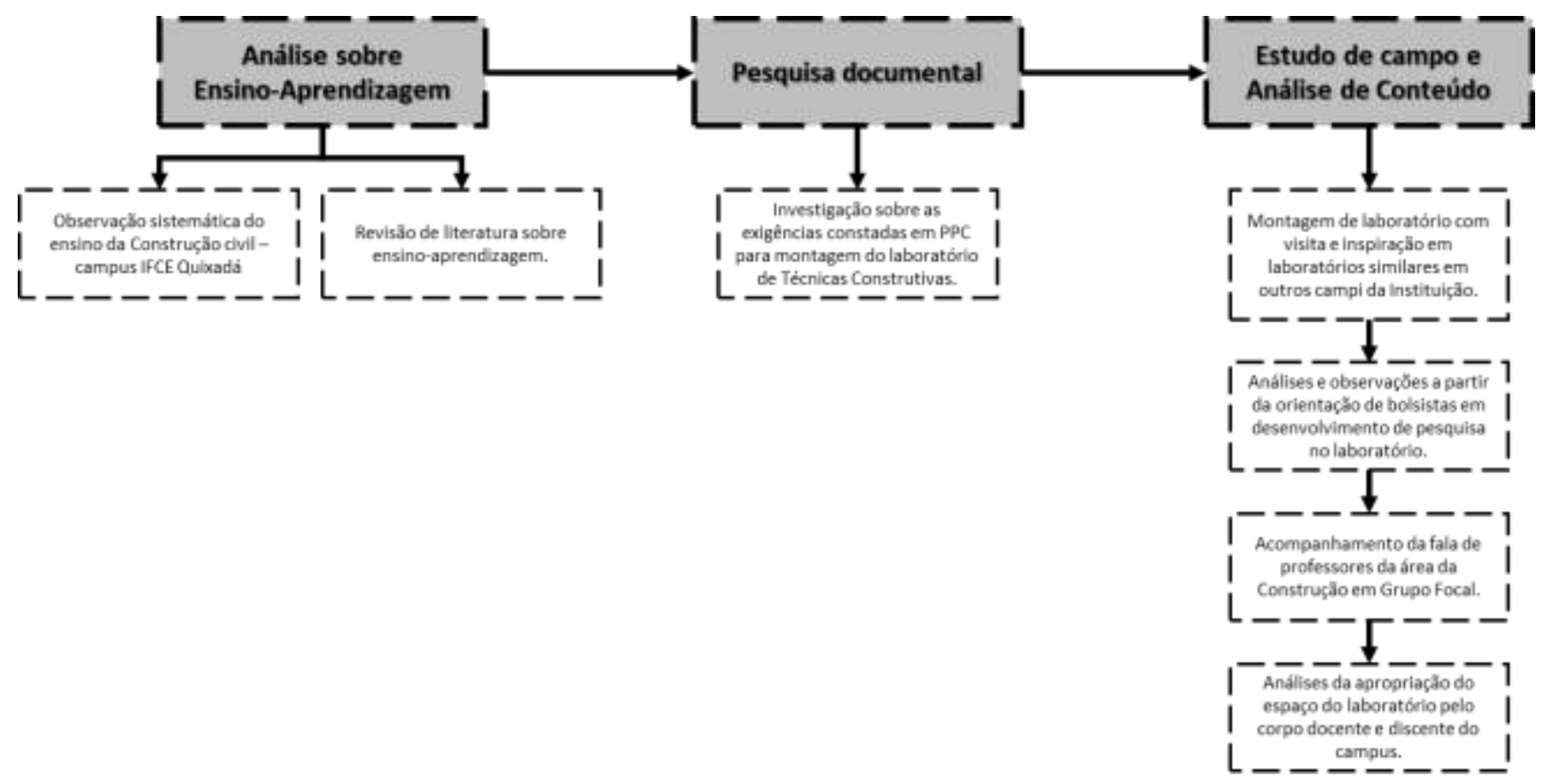

Fonte: Sistematizado pelas autoras.

Primeiramente, foi feita uma etapa de observação do ensino da Construção Civil no campus do IFCE em Quixadá-CE no Brasil, associando-se a isso uma revisão bibliográfica sobre processos de ensino-aprendizagem. Posteriormente, foi feita uma pesquisa documental na leitura das diretrizes institucionais de curso sobre o laboratório de Técnicas Construtivas. Por fim, realizou-se uma etapa de estudo de campo para montagem do laboratório, vendo exemplos de laboratórios similares em outros campi da Instituição; bem como, e principalmente, fazendo-se análises a partir da orientação de bolsistas em desenvolvimento de pesquisa no laboratório, do acompanhamento da fala de professores em Grupo Focal e de análises da apropriação do espaço do laboratório pelo corpo docente e discente do campus.

Segundo Creswell (2007), esses procedimentos mistos de coleta de dados em pesquisa científica visam a uma melhor resposta à necessidade de esclarecer o objetivo; aqui, no caso, de relatar a experiência vivida nesse processo de fortalecimento do ensino-aprendizagem a partir da montagem do laboratório. Além disso, entende-se que é interessante a realização da triangulação de dados para melhor cumprimento da pesquisa. Segundo Zappellini e Feuerschütte (2015), a triangulação é vista como uma técnica que combina diferentes procedimentos de coleta de dados, distintas populações (ou amostras), diferentes perspectivas teóricas e diferentes momentos no tempo para consolidar as conclusões a respeito do fenômeno que está sendo estudado.

Assim, nessa análise, foram consideradas diferentes técnicas de coleta de informações para o presente relato; observaram-se dados administrativos, do corpo docente e discente do campus em estudo e, para embasamento teórico, tiveramse como marcos de referência os textos de Mota et al. (2018) e Saviani (1994, 2007), bem como outras perspectivas de 
pensamentos distribuídas em variados espaços de tempos e localidades.

Como organização dos resultados para obter análises e discussões mais claras, adotaram-se as recomendações de categorização de conteúdos sugeridas por Bardin (2010). Segundo a autora, é importante categorizar e classificar os resultados de forma significativa para trazer mensagens reflexivas e válidas para a comunidade acadêmica.

\section{Resultados e discussões}

Em janeiro de 2018, uma das autoras desse trabalho, com seis meses de ingresso no IFCE, foi designada à coordenação do Laboratório de Técnicas Construtivas do campus de Quixadá. Todavia, aquela não era uma simples atribuição por estar se tratando de um laboratório que ainda não existia de fato, apenas em seu espaço físico (uma sala de aula que se tornaria laboratório). Aquele momento, portanto, tratava-se de um divisor de águas de uma visão meramente tecnicista e laboratorial para uma visão mais detalhada dos processos de ensino-aprendizagem.

A seguir, colocam-se os passos do relato dessa vivência classificados, conforme recomenda Bardin (2010), em categorias para melhor entendimento e organização das informações trazidas. Na categoria de planejamento e montagem do laboratório, foram aprofundadas as questões aqui relatadas, por exemplo, a partir de questionários do tipo survey e entrevistas de Grupo Focal; mas, como o foco desse estudo é voltado para o processo de montagem do laboratório, esses dados de respostas dos entrevistados serão contemplados em outro trabalho.

\subsection{Caracterização do processo de ensino-aprendizagem e justificativa do laboratório}

A partir da atribuição da coordenação de laboratório, deu-se início a uma análise de como vinha sendo o ensino e a aprendizagem nos cursos ligados à Construção Civil do referido campus, a saber: curso Técnico Subsequente e Integrado em Edificações, curso de Engenharia de Produção Civil e, recém-iniciado na época, curso de Engenharia Civil. Logo no início dessas análises, a partir de observações sistematizadas e participantes, começou-se a observar que o ensino das áreas técnicas ligado à Construção Civil carregava muito mais teoria que a abordagem da prática técnica em si. À princípio, aquilo parecia estranho, porque se tratava de uma instituição que nasceu de uma base tecnológica, que é o IFCE, mas que precisava de mais observação por se tratar de um parecer de alguém ainda recém-ingresso. Todavia, percebeu-se que essa instituição se mostrava diferenciada de outras instituições meramente tecnicistas, porque trazia consigo um viés teórico e reflexivo para formar profissionais críticos e conscientes de seu papel na sociedade, conforme aponta Mota et al. (2018). Foi nesse limite tênue que se iniciou uma reflexão sobre o fato de, ao invés dos cursos de graduação ganharem uma abordagem prática por estarem inseridos dentro do IFCE, ocorrer o inverso: os cursos técnicos perdiam seu princípio prático, do "aprender fazendo" como cita Saviani (1994), para um processo de ensino meramente teórico.

Apesar da existência de práticas inseridas dentro dos laboratórios de Materiais de Construção, Mecânica dos Solos e Topografia, observou-se que faltava um espaço para que os discentes pudessem trabalhar os princípios e técnicas das etapas construtivas de uma obra. Nem sempre as visitas técnicas são suficientes para incorporar ao estudante essa visão de mercado. Ademais, existem limitações de número de visitas técnicas, pois envolve custos e tempo dentro de um semestre. Também, por se tratar de um campus localizado no interior do Estado, não existem obras locais suficientes que possam mostrar todas as etapas construtivas nem todas as possibilidades de técnicas disponíveis, sendo esse um fator que não se conseguiria mesmo com visitas a obras na capital.

Com isso, pensando no que falou Corrêa e Naveiro (2001) e Formighieri e Lima (2019) em adequar a dinâmica dos cursos ao perfil de profissional desejado pelo mercado, ratificou-se a importância da existência de um laboratório naquele campus voltado para técnicas de construção, em que o aluno pudesse se apropriar do contato direto com os diversos materiais dessas etapas construtivas, bem como conhecer e saber manusear ferramentas e equipamentos associados a elas. É importante dizer que 
proporcionar experiências como essa ao corpo discente, conforme falava Kolmos e Holgaard (2008), sem dúvidas, traz uma maior sedimentação do conhecimento teórico visto em sala de aula. Além disso, esse tipo de prática vem fortalecer e dar segurança àqueles profissionais voltados para a formação especificamente técnica, de maneira a ingressarem no mercado de trabalho mais conscientes do que irão fazer e sabendo qual seu papel de importância, de acordo com o viés de formação do IFCE.

\subsection{Investigação das recomendações de montagem do laboratório}

Assim, pois, diante dessas reflexões iniciais sobre o processo de ensino-aprendizagem na área de técnicas da construção no campus em estudo, buscou-se recorrer aos Projetos Pedagógicos dos Cursos (PPCs) aqui citados que iriam usufruir daquele espaço laboratorial. Para essa etapa de planejamento do espaço do laboratório, então, fazia-se importante constatar o que diziam os planos de cursos, se mencionavam ou não sua existência e como era sua descrição. No Quadro 1 a seguir, pode-se ver resumidamente os dados coletados.

Quadro 1 - Cursos e suas descrições em PPC sobre o Laboratório de Técnicas Construtivas.

\begin{tabular}{|l|l|}
\hline $\begin{array}{l}\text { Curso de Graduação - Bacharelado em } \\
\text { Engenharia de Produção Civil. }\end{array}$ & $\begin{array}{l}\text { Não trouxe descrição sobre o Laboratório de Técnicas } \\
\text { Construtivas, mas abordou laboratórios similares que estão } \\
\text { absorvidos dentro deste. }\end{array}$ \\
\hline $\begin{array}{l}\text { Curso de Graduação - Bacharelado em } \\
\text { Engenharia Civil. }\end{array}$ & $\begin{array}{l}\text { Não trouxe descrição sobre o Laboratório de Técnicas } \\
\text { Construtivas, nem similar de aplicação dessas técnicas. }\end{array}$ \\
\hline $\begin{array}{l}\text { Cursos Técnicos - Técnico Integrado em } \\
\text { Edificações e Técnico Subsequente em } \\
\text { Edificações. }\end{array}$ & $\begin{array}{l}\text { Não trouxe descrição sobre o Laboratório de Técnicas } \\
\text { Construtivas, nem similar de aplicação dessas técnicas. }\end{array}$ \\
\hline
\end{tabular}

Fonte: Sistematizado pelas autoras.

Como é percebido no Quadro 1, a partir do resumo de análise dos PPC's dos cursos técnicos e de graduação do IF campus de Quixadá, apenas o curso Bacharelado em Engenharia de Produção Civil traz algo na linha de funcionamento parecido com o laboratório de Técnicas Construtivas. São esses os laboratórios citados no PPC do curso de Produção Civil:

a) Laboratório de Instalações Prediais contendo bancadas de alvenaria/concreto armado para realização de práticas de instalações, bancos (12) para as bancadas, quadro branco, carteiras individuais (15 a 20 unidades), prateleiras, mostruários de materiais de instalações prediais. Este laboratório irá atender às disciplinas de Instalações Elétricas Prediais e Instalações Hidrossanitárias Prediais.

b) Laboratório de Projetos de Construção Civil que se destina à realização de pesquisas e aulas práticas pelos professores e alunos de graduação em Engenharia de Produção Civil nas seguintes áreas: projetos arquitetônicos sustentáveis, eficiência energética de edificações, prototipagem 3D, inovação de produtos e modelagem da informação na Construção Civil (BIM).

\subsection{Planejamento e montagem do espaço laboratorial de Técnicas Construtivas}

Com poucas informações nos PPC's de como devia ser montado esse laboratório, passou-se, então, ao que Bardin (2010) chama de leitura flutuante, realizando a busca por novos conteúdos que podiam servir de base para a construção desse espaço. Assim, buscou-se: a observação de laboratórios em outros campi, o fomento de pesquisa com alunos para montagem desse espaço, o acompanhamento de opiniões de professores a partir de Grupo Focal, e a análise da apropriação pelo corpo docente e discente do espaço do laboratório.

\subsubsection{Observação de laboratórios em outros campi}


Diante do exposto, partiu-se então para conhecer outros laboratórios nessa vertente da Construção Civil dentro da rede do IFCE. Conheceu-se, informalmente, por foto, o laboratório de técnicas para Instalações Prediais do campus de Crateús e, pessoalmente, conheceu-se um laboratório no mesmo estilo no campus de Morada Nova. Foi percebido que o viés de laboratório nessa vertente segue mais para experimentos de Instalações Prediais; seria novo, portanto, um laboratório que agregasse outros passos de técnicas para montagem da edificação. Somando-se a essa ideia inicial, agregou-se uma experiência da autora em montagem de parte do laboratório de técnicas construtivas, também na parte de Instalações Prediais, em uma faculdade da rede privada anos antes de ingressar no IF. Assim, foi possível se pensar na configuração inicial de como era esperado o referido laboratório no campus de Quixadá.

Informalmente, foi tomado conhecimento que, no referido campus, em épocas atrás, quando se tinha apenas o curso Técnico em Edificações (do eixo da Construção Civil), existiam professores que traziam uma abordagem mais tecnicista, fazendo testes em algumas disciplinas e associando a prática do "aprender fazendo" ao conteúdo teórico abordado. Como até aquele momento não existia o laboratório de Técnicas Construtivas, que estava nascendo a partir desse estudo, alguns insumos eram guardados no laboratório de Materiais de Construção, e, ali mesmo, era o local onde as turmas faziam seus testes de aulas práticas, mas que, atualmente, já não se aplicava mais. Isso se deveu ao fato de o campus ter crescido e, mesmo que fosse tentado permanecer aqueles insumos no laboratório de Materiais de Construção, seria difícil conjugar as aulas práticas ligadas às Técnicas de Construção com as aulas de Materiais. A demanda do campus só foi crescendo, pois surgiram os cursos de Engenharia de Produção Civil e Engenharia Civil, além do curso de Engenharia Ambiental que também tem disciplinas no laboratório de Materiais de Construção. Dessa forma, as aulas práticas voltadas para as disciplinas que envolvessem técnicas construtivas estavam esquecidas e mereciam, de fato, um espaço próprio, de maneira a não se perder o viés do "aprender fazendo" citado por Saviani (1994), que o IF possui em seu princípio de formação, como sugere Mota et al. (2018).

Assim, portanto, com a criação de um espaço individual para esse laboratório, percebe-se que tanto a graduação ganharia em ter mais apropriação do que está aprendendo na teoria como os cursos técnicos resgatariam esse viés tecnicista que estava se perdendo no campus, de acordo com as observações já mencionadas. Isso vem ao encontro da recomendação de Barato (2015a, 2015b) sobre o cuidado de não se negligenciar a prática no ensino profissional e a importância de não se deixar enfraquecer o uso de laboratórios nessas Instituições.

Dessa forma, aquele espaço de sala vazia destinada ao laboratório de Técnicas Construtivas ganhou os insumos que estavam guardados no laboratório de Materiais de Construção, mais alguns mobiliários que estavam sem uso no almoxarifado e, assim, deu-se início ao processo de montagem. Ali ainda era muito incipiente, três mesas no formato de birôs, dois tampos para prateleira e duas estantes metálicas com alguns materiais de mostruário e umas três ferramentas. Isso ficava perdido dentro daquela imensa sala, o que levou a se pensar em uma configuração para incrementar o espaço com algumas carteiras ao centro, visto que não havia bancadas já construídas, como é comum em laboratórios (Figura 3). 


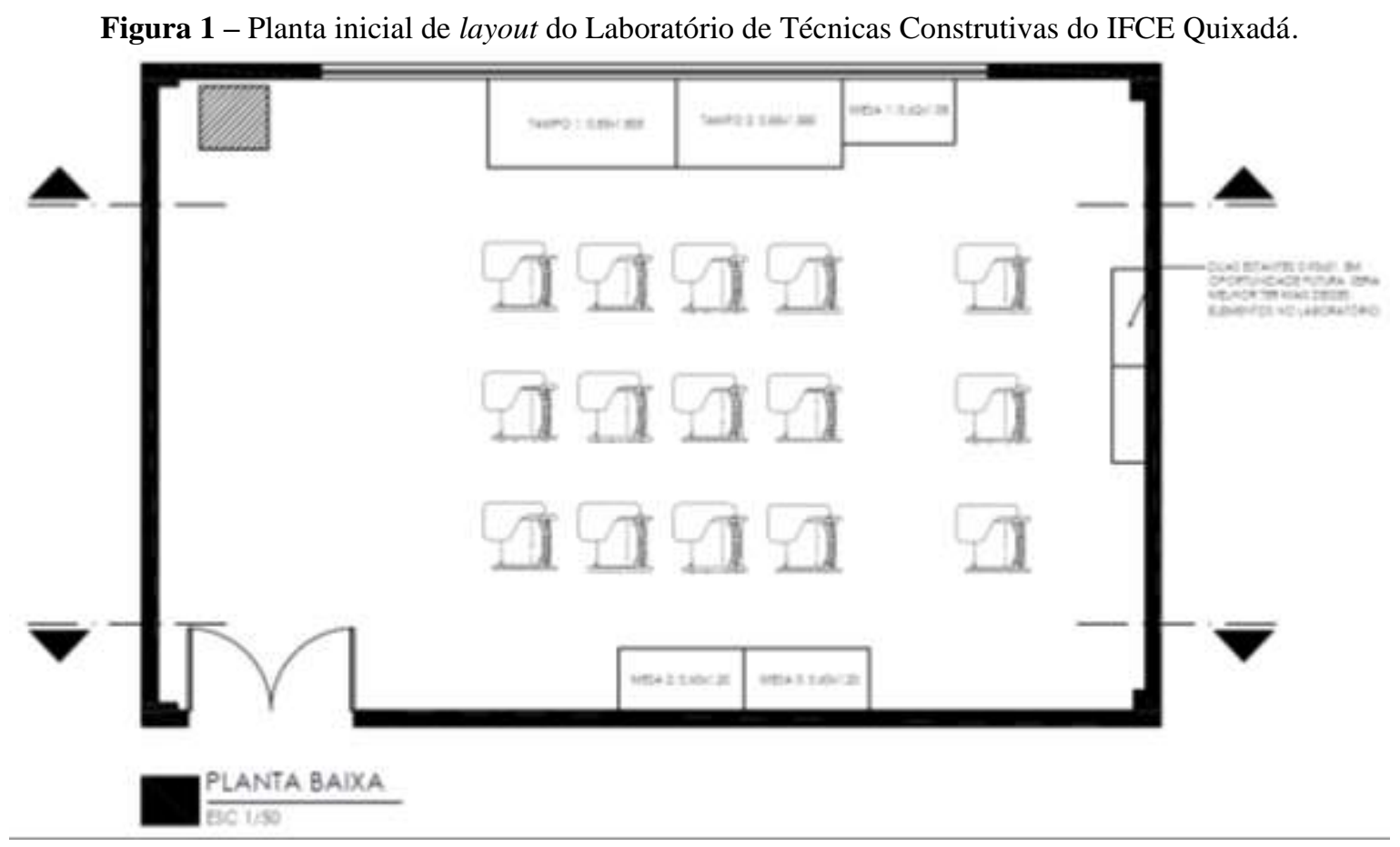

Fonte: Sistematizado pelas autoras.

Nessa configuração de carteiras ao centro, portanto, o espaço mostrou-se convidativo também para a existência de aulas teóricas convencionais, além de aulas associadas ao mostruário ali exposto no laboratório.

\subsubsection{Fomento de pesquisa para auxilio na montagem do laboratório}

Então, tinha-se uma sala, alguns elementos, mas faltava o mais importante: envolvimento de alunos e professores dentro daquele espaço. Havia muito a se caminhar ainda e, então, foi tomado por bem agregar mais pessoas ao processo e associar pesquisa para maior aprendizagem coletiva, como sugeriu Kolmos e Holgaard (2008). Surgiu assim a pesquisa de extensão ligada à Coordenadoria de Assuntos Estudantis (CAE), intitulada como "O impacto do olhar ilustrativo sobre o índice de aprendizagem discente em disciplinas de Construção Civil”. Essa pesquisa agregou, em princípio, uma aluna bolsista por meio do auxílio formação e um aluno voluntário, que vinham a ser também entusiastas para construção do referido laboratório. Nessa etapa, aplicou-se uma pesquisa de survey junto a alunos (339 respostas) e professores ( 7 respostas) para coletar informações sobre como esses viam e como desejavam o processo de ensino-aprendizagem na área da Construção Civil no IF Quixadá1. Nessa etapa, procurou-se mesclar algumas questões do método Index of Learning Style (ILS) de Felder e Soloman (1991) para conhecer as preferências de aprendizagem desse grupo dentro do IF, e questões de Bernardinis et al. (2017) para analisar o processo de ensino.

Também, nessa época, começou-se uma campanha do laboratório para aquisição de insumos doados, conseguindo-se alguns elementos de Instalações Hidrossanitárias, um painel de Instalações Elétricas e uma amostragem de diferentes tipos de blocos cerâmicos, mais algumas promessas. Também foram levantadas listas de ferramentas e equipamentos que poderiam agregar valor ao espaço e que poderiam ser adquiridos via orçamento do IFCE. Ademais, conseguiu-se, junto à instituição, algumas peças de divisórias de estações de trabalho que não estavam sendo utilizadas e que passaram a compor uma imagem de prateleiras nas paredes do laboratório. Isso deu uma boa possibilidade para o layout desejado, com carteiras ao centro e mostruário de insumos e ferramentas por toda a volta da sala (conforme visto na Figura 3). Além disso, o laboratório ganhou

${ }^{1}$ Como o foco desse artigo é voltado para o processo de montagem do laboratório, esses dados de respostas dos entrevistados serão contemplados em outro trabalho. 
uma sigla, LABTECON (Laboratório de Técnicas Construtivas), uma logo e uma placa para ser colocada na porta da sala. O campus também cedeu uma lousa digital que não estava sendo usada e que passaria a compor uma metodologia de ensino junto aos insumos e ferramentas do laboratório. Começou-se, então, junto aos alunos, a se trabalhar em maquetes virtuais com a aplicação prática das técnicas que o laboratório estava se propondo a trazer.

Posteriormente, através de uma pesquisa (intitulada "Laboratório de Técnicas Construtivas enquanto suporte para o Ensino e Aprendizagem em disciplinas ligadas à Construção Civil”) em continuidade para troca de bolsista junto à CAE, conseguiu-se mais uma bolsa de auxílio formação, ficando dois novos alunos bolsistas no laboratório. Todavia, os dois antigos alunos que começaram a pesquisa permaneciam no grupo como voluntários. Foi, então, que se cadastrou uma pesquisa complementar junto à plataforma $\mathrm{NL}^{2}$ do IFCE (intitulada “Análise do ensino-aprendizagem em disciplinas ligadas à Construção Civil no campus do IFCE de Quixadá”), garantindo que os alunos voluntários pudessem constar comprovação de suas dedicações e tempo para auxílio ao laboratório. Apesar dos nomes das pesquisas serem parecidos, cada uma possuía abordagem complementar de continuidade para uma montagem de laboratório coletiva, consciente e com um viés de resgate do processo de ensino-aprendizagem a partir do princípio do "aprender fazendo".

\subsubsection{Acompanhamento de professores em Grupo Focal sobre ensino-aprendizagem}

O processo de "ensinar fazendo" gera por si só o envolvimento coletivo das disciplinas e, com isso, traz o fomento da interdisciplinaridade. De acordo com o que foi dito por Puhl e Dresch (2016), que a interdisciplinaridade gera o fortalecimento do ensino e favorece a resolução de problemas da sociedade, pensou-se em confrontar opiniões dos professores das diversas subáreas dentro da Construção Civil. Isso, inclusive, vem ao encontro do que comenta Vega et al. (2020), que é necessário primeiro o assunto estar presente no diálogo dos professores para que criem vínculos que se estendam aos saberes disciplinares.

Nesse tempo, tomando como base a experiência de participação em grupos focais no trabalho do Grupo de Pesquisa e Assessoria em Gerenciamento na Construção Civil - GERCON (2015), foi aplicado um Grupo Focal junto ao corpo docente que tinha disciplinas ligadas à construção, dentro do eixo da Construção Civil. Foram, ao todo, oito professores que se reuniram durante duas horas e meia em uma entrevista de grupo guiada e planejada pela equipe do laboratório. O momento foi gravado em áudio e vídeo pela equipe de audiovisual do campus para posteriores análises ${ }^{3}$.

Analisaram-se tópicos como processo de ensino-aprendizagem, métodos avaliativos, além de percepções e necessidades docentes e discentes, sempre utilizando-se de roteiros guiados, cartões de jogos dinâmicos e uma mediadora que não fazia parte da pesquisa, de forma a não tendenciar respostas. A coordenadora do laboratório e autora desse trabalho ficou, durante toda a ocasião, como componente de observação direta sem intervir em falas. Já os alunos bolsistas e voluntários ficaram auxiliando nos registros fotográficos dos resultados de montagens dos jogos e das dinâmicas do grupo. Os alunos transcreveram todo o material e foram feitos cruzamentos de dados com a pesquisa survey incialmente aplicada no começo da montagem do laboratório (que também possuía os mesmos tópicos de abordagem de perguntas). Foram etapas muito ricas que agregaram valor a todo o grupo, gerando resumos para os encontros do Universo IFCE e outras pesquisas.

\footnotetext{
${ }^{2}$ A Plataforma NL é responsável por catalogar projetos submetidos aos editais de financiamento interno do IFCE, bem como permite o envio de propostas para projetos de pesquisa voluntária, cujo fluxo é contínuo ao longo do ano. Link da plataforma:

http://prpi.ifce.edu.br/nl/app_Login/ (acesso em: 17 nov. 2020).

${ }^{3}$ Como o foco desse artigo é voltado para o processo de montagem do laboratório, esses dados de respostas dos entrevistados serão contemplados em outro trabalho.
} 


\subsubsection{Análise do engajamento da comunidade acadêmica}

Na segunda metade do ano de 2019, havendo troca de bolsistas, ficaram ao todo seis alunos ligados ao laboratório, alguns voluntários, outros com bolsa de extensão. Percebia-se, então, que os alunos começavam a tomar gosto em participar de algo que envolvesse diretamente as técnicas e práticas construtivas. Isso demonstrava um resgate inicial do "aprender fazendo" dentro dessa área no campus (como foi citado no item 4.3.1, em tempos atrás, existiam professores que traziam uma abordagem mais tecnicista, mas esta foi se perdendo pela própria falta de espaço específico voltado para tal fim).

Adicionada à contribuição direta dos bolsistas e voluntários junto à coordenação do laboratório, outro professor contribuiu com o fomento de um grupo de estudo com professores e alunos dentro desse espaço laboratorial. Isso ajudou a buscar na sociedade local oportunidades de discussões, trazendo questões reais de trabalho e problemas a serem solucionados e analisados pela comunidade acadêmica. Essa ação veio corroborar com a possibilidade de melhoraria das atividades das disciplinas dessa área a partir de simulações baseadas em exercícios da prática profissional, o que, conforme fala Formighieri e Lima (2019), pode fortalecer as metodologias interdisciplinares de ensino-aprendizagem. Dessa maneira, com o início de análises práticas estudadas no laboratório, percebia-se que era possível aproximar os alunos da sociedade e incentivá-los a serem capazes de resolver problemas que o mundo real apresenta, além de meramente buscarem aprovações nas disciplinas exigidas pelos cursos, conforme apontava Bernardinis et al. (2017).

Essas ações fizeram uma grande diferença de imagem do referido espaço, pois ele passou a ser mais visto e mais visitado. Antes, mesmo informando que o ambiente era para a adoção de aulas práticas ligadas às diferentes disciplinas que abordassem técnicas construtivas, parecia que a ideia da aplicação de um conteúdo meramente teórico era mais fácil e mais cômoda e estava já se enraizando pelo campus (na área da técnica de Construção Civil), não havendo procura inicial do espaço criado para aplicação prática de ensino. O surgimento do grupo de estudo, então, veio somar forças para a continuação da empreitada do laboratório e, conforme Barato (2015a, 2015b), não deixar cair em esquecimento o uso de aulas práticas como incentivo ao ensino, à pesquisa e à extensão.

Assim, foi-se percebendo que o espaço ganhava crédito junto ao corpo discente e docente. Com as visitas mais frequentes dos professores ao espaço laboratorial, começou-se a observar o interesse em contribuir para a melhoria do ambiente, favorecendo as práticas de ensino, aprendizagem e estudos diversos. Houve a contribuição de outros professores para a organização dos materiais nas prateleiras seguindo o processo de etapas construtivas (Figura 4 -a), bem como o incremento de maquetes em pequenas escalas e protótipos em tamanhos reais no laboratório, produzidos por atividades parciais de disciplinas. Na Figura 4 - b, mostra-se um protótipo em tamanho real feito por uma professora do campus junto aos alunos no laboratório de Técnicas Construtivas. 
Figura 2 - Fotos atuais do Laboratório de Técnicas Construtivas do IFCE campus Quixadá.

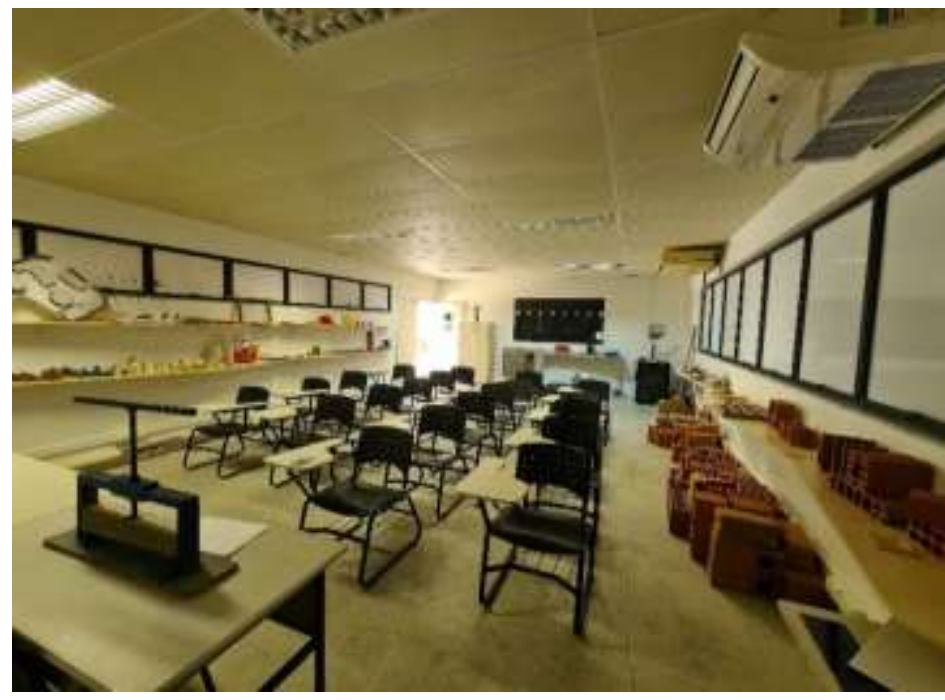

a - Vista da organização dos insumos e maquetes nas prateleiras do Laboratório de Técnicas Construtivas

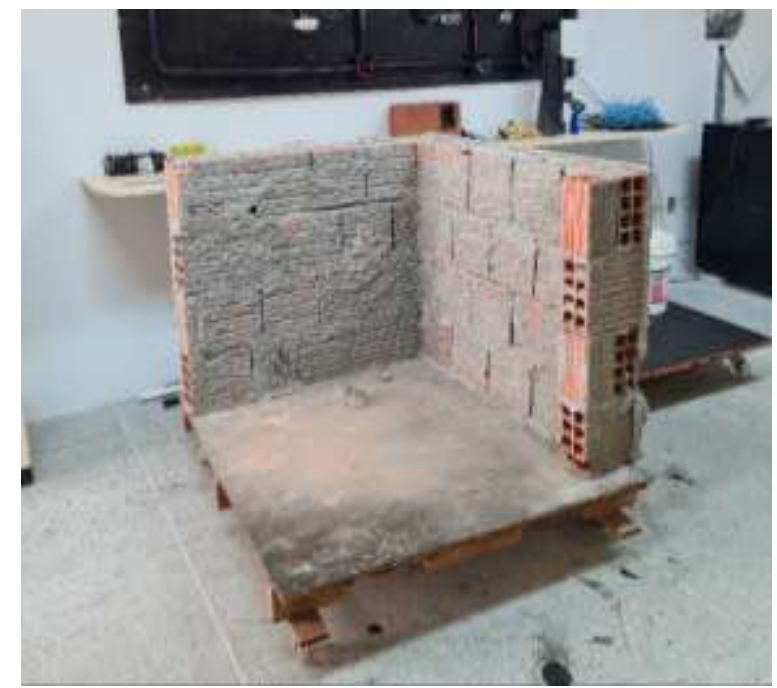

b - Protótipo em tamanho real feito no Laboratório de Técnicas Construtivas

Fonte: Registrado pelas autoras.

Como apropriação do espaço do laboratório pelo corpo discente, além do próprio aumento de visitação e envolvimento dos alunos, também pode-se registrar aqui, com a devida autorização dos estudantes, a produção de uma maquete virtual do laboratório (Figura 5) a fim de gerar um mapa de riscos, produto de uma disciplina sobre Higiene e Segurança do Trabalho.

Figura 3 - Imagens de protótipo virtual do Laboratório de Técnicas Construtivas - IF Quixadá.

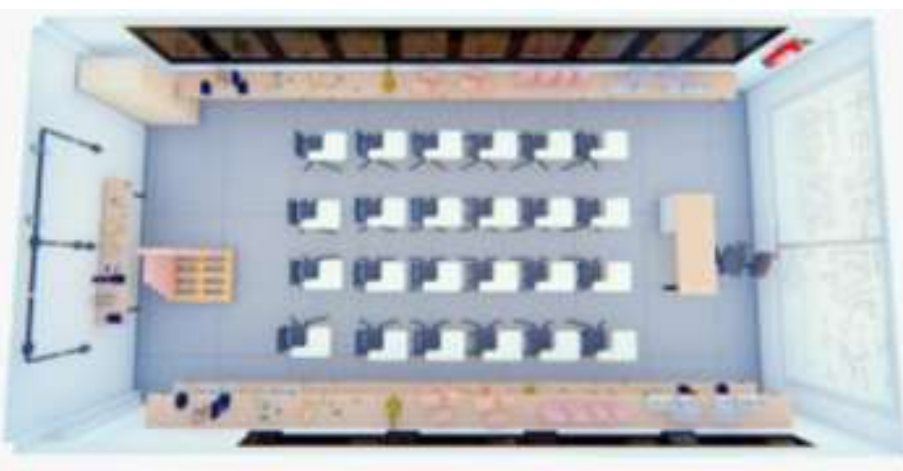

a - Vista virtual aérea do Laboratório

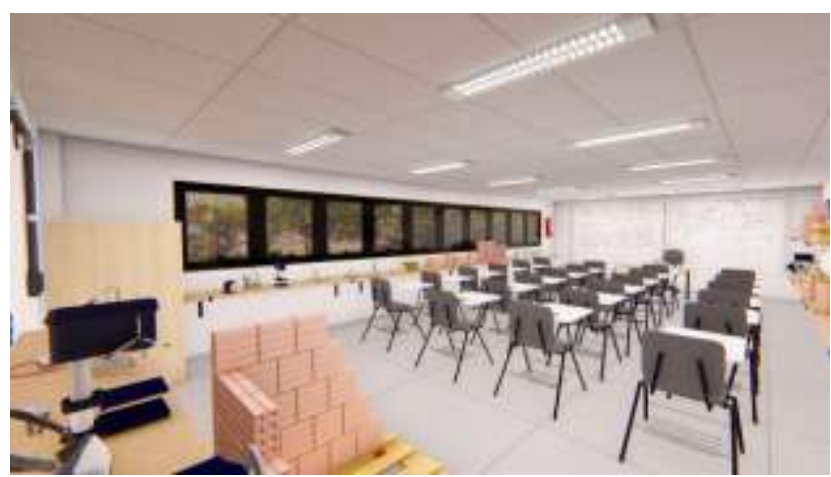

b - Vista virtual lateral do Laboratório

Fonte: Imagens elaboradas e cedidas pelos alunos do $4^{\circ}$ semestre de Engenharia Civil do IF Quixadá.

Como produto, pois, dessa disciplina e dessa apropriação dos alunos, gerou-se algo que agregou valor ao laboratório: o seu Mapa de Riscos, visto na Figura 6. 
Figura 4 - Mapa de Riscos do Laboratório de Técnicas Construtivas - IF Quixadá.

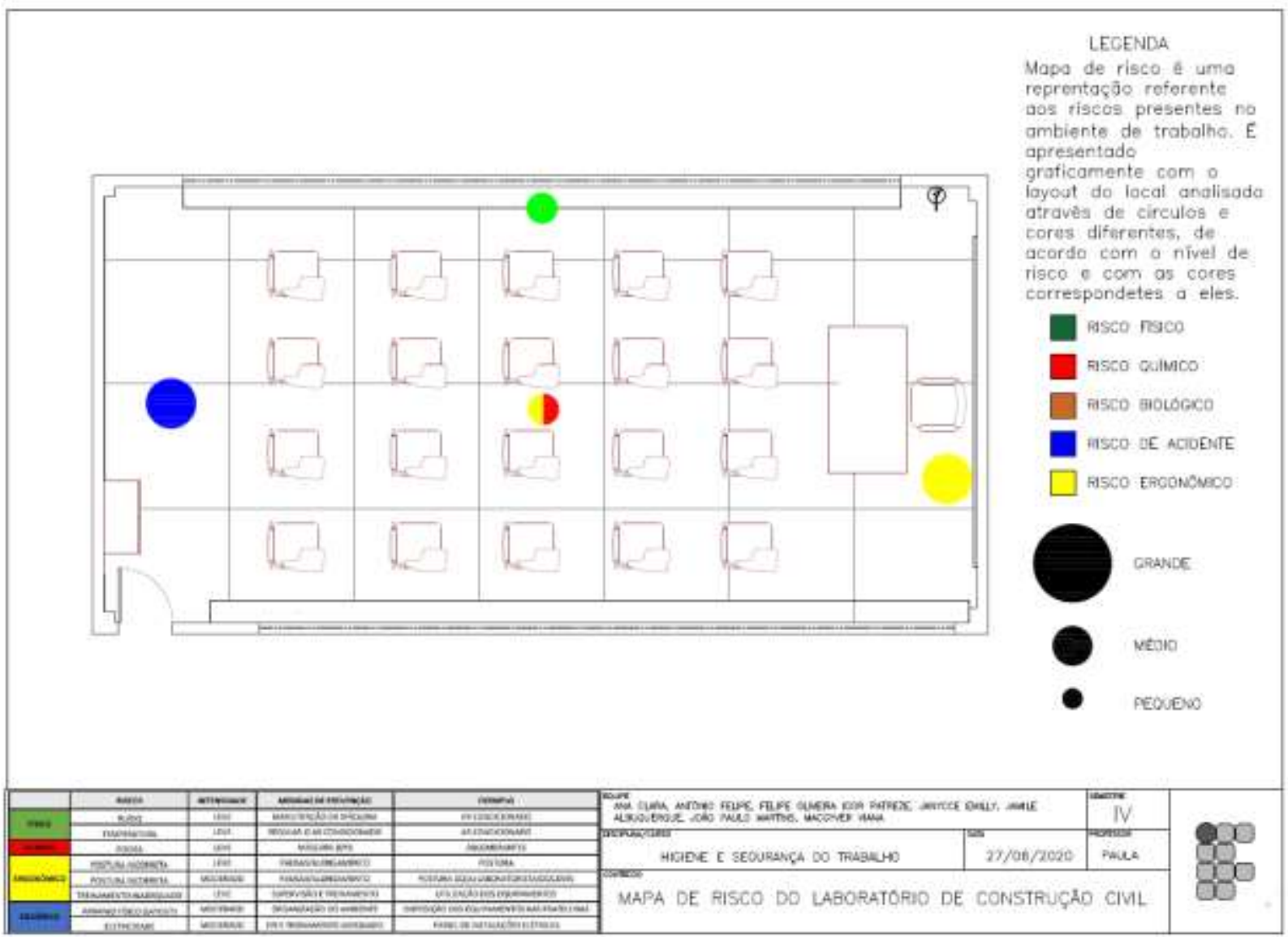

Fonte: Elaborado e cedido pelos alunos do $4^{\circ}$ semestre de Engenharia Civil do IF Quixadá.

Com esse estudo, pode-se constatar que a montagem do laboratório em si já foi um experimento diferenciado para professores e alunos, pois trouxe consigo a oportunidade de se analisar o processo de educação e sua relação de importância com uma raiz laboral. Foi possível resgatar a verdadeira importância da educação no processo de transformação do meio (trabalho) em prol da melhoria coletiva da sociedade.

\section{Considerações Finais}

Com essa pesquisa, durante o relato das etapas de montagem do laboratório, pode-se analisar pontos relevantes de ensino-aprendizagem na área da Construção Civil e perceber na prática como o laboratório pode ajudar na reaproximação entre educação, trabalho e sociedade.

Foi percebido que o processo de ensino-aprendizagem requisita uma análise prévia de como os alunos de um grupo se comportam com a assimilação de novos conteúdos, o que se recomenda a aplicação do questionário Index of Learning Style (ILS) de Felder e Soloman (1991) para se definir os estilos adequados de aprendizagem para cada situação. Para estudantes das áreas de engenharias, que normalmente se configuram como ativos, sensíveis e visuais, o uso de laboratórios se apresenta como solução relevante a se adotar. Na parte do ensino, é possível dizer que a interdisciplinaridade pode ser a base para conduzir estudos laboratoriais na área da Construção Civil, despertando processos comparativos entre teoria e prática que venham a facilitar o entendimento dos diversos conteúdos. De um modo geral, o que se percebe é que os alunos e professores da área da Construção Civil do IF Quixadá sentem-se confortáveis com a ideia de um laboratório para desenvolverem pesquisas interdisciplinares e associadas a estudos de casos reais da comunidade local, protótipos de análises experimentais de suas aulas, bem como se mostram acolhidos em um espaço que serve de mostruário dos insumos similares aos da prática profissional. 
Assim, a ideia da construção e do uso do laboratório de Técnicas Construtivas no IF campus de Quixadá é aliar o saber científico do ensino, os recursos e as técnicas disponíveis percebidos na pesquisa e extensão universitária e, com isso, aplicar a pesquisa laboratorial para a inovação do aprendizado em prol da comunidade. Dessa forma, espera-se que o uso desse laboratório traga resultados na melhoria de técnicas da Construção Civil local, resultando em benefícios para a sociedade a partir desses profissionais que sairão dos muros acadêmicos já inseridos no contexto profissional, de forma consciente, flexível e seguros de seus saberes.

Ao fim, constata-se que cada etapa do percurso metodológico citado nesse trabalho foi de suma importância para a construção coletiva desse laboratório, como a observação sistemática, a pesquisa documental e, principalmente, a pesquisa de campo feita no IF. Com isso, foi possível relatar o processo de montagem do laboratório de Técnicas Construtivas no campus de Quixadá, considerando análises críticas sobre o favorecimento do ensino e da aprendizagem em espaços como esse. O processo de melhoria tem se mostrado lento, porém natural e espontâneo na apropriação do espaço pela comunidade acadêmica. Na verdade, ainda há muito o que se caminhar, é preciso enriquecer mais o laboratório e diluir de vez barreiras que estavam se fortalecendo para dar espaço ao ensino técnico aplicado junto ao conteúdo teórico. O objetivo principal com tudo isso, portanto, é formar profissionais seguros e conscientes de seu papel no mercado de trabalho e na sociedade em que estão inseridos.

\section{Agradecimentos}

Ao IFCE campus Quixadá, por proporcionar a oportunidade de montagem desse espaço de trocas coletivas e interdisciplinares de ensino e aprendizagem.

\section{Referências}

Barato, J. N. (2015a). Educação Técnica e profissional. Sala Debate. Canal Futura. https://www.youtube.com/watch?v=ifMZt8A7oCg

Barato, J. N. (2015b). Fazer bem feito: valores em educação profissional e tecnológica. UNESCO.

Bardin, L. (2010). Análise de conteúdo. (4a ed.), Edições 70.

Bernardinis, M. A. P., Zau, S. K. S., \& Pacheco, E. (2017). Um estudo da correlação entre o estilo de aprendizagem dos alunos e docentes do curso de Engenharia Civil da Universidade Federal do Paraná. Revista Principia - Divulgação Científica e Tecnológica do IFPB, 116-123. http://dx.doi.org/10.18265/1517$03062015 \mathrm{v} 1 \mathrm{n} 34 \mathrm{p} 116-123$

Cardoso, I. M., \& Silva Lima, R. da. (2012). Métodos Ativos de Aprendizagem: o uso do aprendizado baseado em problemas no ensino de logística e transportes. Transportes, 79-88. https://doi.org/10.4237/transportes.v20i3.561

Corrêa, R. M., \& Naveiro, R. M. (2001). Importância do ensino da integração dos projetos de arquitetura e estrutura de edifícios: fase de lançamento das estruturas. In: III Workshop Nacional Gestão do Processo de Projeto na Construção de Edifícios. Anais... USP.

Creswell, J. W. (2007). Projeto de pesquisa: métodos qualitativo, quantitativo e misto. Tradução de Luciana de Oliveira da Rocha. (2a ed.), Artmed/Bookman.

Felder, R. M., \& Spurlin, J. (2005). Applications, reliability and validity of the index of learning styles. International Journal of Continuing Engineering Education and Life-Long Learning, 103-112. https://wss.apan.org/jko/mls/Learning\%20Content/ILS_Validation(IJEE).pdf

Felder, R. M., \& Soloman, B. A. (1991). Index of Learning Styles (ILS). https://www.webtools.ncsu.edu/learningstyles/

Formighieri, D. V. G., \& Lima, J. Q. (2019). Ensino de desenho técnico e arquitetônico: uma proposta de exercícios interdisciplinares de representação gráfica. Research, Society and Development, e168101340. https://doi.org/10.33448/rsd-v8i10.1340

Frigotto, G. (2001). Educação e trabalho: bases para debater a Educação Profissional Emancipadora. Perspectiva, Florianópolis, 71-87. https://periodicos.ufsc.br/index.php/perspectiva/article/view/8463

GIL, A. C. (2007). Como elaborar projetos de pesquisa. (6a ed.), Atlas.

Grupo de Pesquisa e Assessoria em Gerenciamento na Construção Civil - GERCON. (2015). Proposta de melhoria dos projetos dos empreendimentos do programa Minha Casa Minha Vida a partir de avaliação de satisfação dos clientes. Barros Neto, J. P. (Coord). Relatório de Pesquisa CNPq. Universidade Federal do Ceará - UFC.

Kolmos, A., \& Holgaard, J. E. (2008). Learning styles of science and engineering students in problem and project based education. In Book of Abstracts. Brill | Sense. https://vbn.aau.dk/ws/files/55271935/learning_styles_of_science.pdf 
Research, Society and Development, v. 10, n. 5, e23510514883, 2021

(CC BY 4.0) | ISSN 2525-3409 | DOI: http://dx.doi.org/10.33448/rsd-v10i5.14883

Mota, K. R., Araújo, C. H. S., \& Santos, B. G. (2018). A formação para o trabalho: o papel dos Institutos Federais na produção dos novos intelectuais. HOLOS, 351-364. https://doi.org/10.15628/holos.2018.7120

Pereira, M. A. (2005). Ensino-Aprendizagem em um contexto dinâmico: o caso de planejamento de transportes. 2005.129 f. Tese (Doutorado em Engenharia Civil) - Escola de Engenharia de São Carlos, USP, São Carlos. https://www.teses.usp.br/teses/disponiveis/18/18137/tde-17062005-182009/pt-br.php

Puhl, M. J., \& Dresch, Ó. I. (2016). O princípio da indissociabilidade entre ensino, pesquisa e extensão e o conhecimento. Di@logus, 37-55. http://www.revistaeletronicaocs.unicruz.edu.br/index.php/Dialogus/article/view/3991

Saviani, D. (1994). O trabalho como princípio educativo frente às novas tecnologias. In: Ferreti, C. et al. Novas tecnologias, trabalho e educação: um debate multidisciplinar (pp. 147-164). Vozes.

Saviani, D. (2007). Trabalho e educação: fundamentos ontológicos e históricos. Revista brasileira de educação, 152-165. https://www.scielo.br/pdf/rbedu/v12n34/a12v1234.pdf

Silva Júnior, C. A. P., Fontenele, H. B., \& Silva, A. N. R. (2013). Estilos de ensino vs estilos de aprendizagem no processo de ensino-aprendizagem: uma aplicação em transportes. Transportes, 30-37. https://doi.org/10.4237/transportes.v21i2.686

Silveira, D. T., \& Córdova, F. P. (2009). A pesquisa científica. In: Gerhardt, T. E.; Silveira, D. T. Métodos de pesquisa (p. 120). Editora da UFRGS.

Valêncio, N. F. L. S. (2000). A indissociabilidade entre ensino/pesquisa/extensão: verdades e mentiras sobre o pensar e o fazer da Universidade Pública no Brasil. Revista Proposta, Rio de Janeiro. http://www.bibliotecadigital.abong.org.br/handle/11465/1346

Vega, A. P. V., Ribeiro, B. C., Padova, L. C., \& Ghisleni, T. S. (2020). Interdisciplinaridade na produção de conteúdos educacionais: a relação teoria e prática. Research, Society and Development, e128911791. http://dx.doi.org/10.33448/rsd-v9i1.1791

Zappellini, M. B., \& Feuerschütte, S. G. (2015). O uso da triangulação na pesquisa científica brasileira em administração. RAEP, Administração: ensino e pesquisa, 241-273. https://doi.org/10.13058/raep.2015.v16n2.238 